\title{
Research on Performing Techniques and Philosophical Connotation of Mahler's Symphony
}

\author{
Wenjie Hao \\ Music College, Baotou Teachers' College, Baotou, 014030, China
}

Keywords: Mahler’s symphony, Performing techniques, Philosophical connotation

\begin{abstract}
Gustav Mahler is a late romantic master, an outstanding conductor and composer. His symphonies have made great breakthroughs in the selection of composing materials, techniques, instruments as well as the size of the band. The techniques of Mahler's symphony are also different from other symphony. By examining all Mahler's symphonies, it can be seen that his thinking about the meaning of life runs through his entire artistic career. This paper analyzes the performing techniques and philosophical connotation of Mahler's symphony to provide some references for the relevant researchers.
\end{abstract}

\section{Introduction}

Gustav Mahler, a famous Austrian conductor and composer, was one of the important representatives of late romanticism [1]. As a musician with a dual identity of conductor and composer, Mahler was widely praised in the field of conductor in his lifetime, but his ability in composing and his works were not given due attention. It was not until the 1980's that his music was gradually recognized and affirmed. Today, Mahler has been regarded as one of the most important composers in the history of music. Austrian composer Mahler, like Beethoven, Wagner and Schoenberg, has attracted much attention among the intellectuals of Western countries. Especially since the 1960s, Western intellectuals have been greatly interested in Mahler's music. Mahler's symphonies have become one of the most popular repertoires in concerts all over the world. The issue quickly caters to this trend of "Mahler Music Craze". Some Western commentators even believe that the revival of Mahler's music has arrived. Mahler's symphonies have attracted so much attention, on the one hand, of course, is the unique charm of his music movement. The beauty of melody, texture, structure and timbre fascinates the appreciator with higher musical accomplishment, but more importantly, the philosophical implication of musical symbols makes the acceptor have some strong spiritual identity. The structure of the four movements of the German-Austrian classical symphony was founded by Haydn, and it was not until Beethoven's time that it was perfected and established. Although symphonic poems have some limitations in choosing themes and contents, this spirit of reform, which dares to break through the tradition, has been inherited and brought into full play in Mahler's hands [2].

\section{Performing Techniques of Mahler's Symphony}

\subsection{Subject Content}

The Third Symphony is one of the most exciting and singing symphonies created by Mahler [3]. Music is rich in content, full of his thinking about life - that is, love nature, love life philosophy. It develops from weak to strong, from small to large. In fact, it is Mahler's praise of the great and tenacious vitality. At the same time, the first movement is also the longest movement written by Muller, which takes about half an hour. Though very long, it is not dull at all. The music is clear and melodic. The whole movement is a variant structure of sonata form. Within the framework of the main body of the music, the first movement highlights the voice of the brass pipe, showing a 
magnificent and majestic main tone from the beginning of the first horn melody. In the voice of the brass tube, the two instruments of trumpet and trombone are highlighted. The trombone's deep and powerful solo drives the progress of the music, making the whole music full of moving and great strength. The theme of the trombone playing in the middle of the movement echoes with the trumpet. The depression of the trombone and the lightening of the trumpet made the audience reach the high mountains and deep canyons. The March is cheerful and contains elements of German Austrian folk music and popular elements. The melodies of the clarinet echoing the violin led the band into a gradual superposition, increasing the number of voices while making the band sound thick and reach its first peak. Then, after a moment of silence, the low Trombone solo sounds played again, giving the impression that the primitive forces of nature in the distance beckon us. Finally, in the trumpet and Trombone solo voice, all bands entered the final peak. On the whole, the whole movement of Muller coexists with the mystique and desire, and is magnificent. The long and strong sound of Trombone solo passages is also a golden color in this movement. It shows the power and appeal of music.

\subsection{Performance Style}

When we practice and play this piece of music, we should try to translate it carefully so that we can understand their exact meaning. It will more accurately grasp the composer's style of playing. Of course, it can still highlight the artistic creation and artistic expression of the performer. In performing the solo passage of this symphony, the majesty and great enthusiasm of triumph should not be rigid or sharp in connection with the key words in the solo, and all performances should imitate the soft and emotional singing of the baritone. The number is four notes, and the beginning is second. The second section is a Trombone solo. It means your time to lose yourself. Later, he emphasized that what he said was not to worry. The composer's approach is to hope that there are more performers here with their own emotions in the music. There will be plenty of time to complete the fade and fade. We can imagine this melody as beautiful as possible. Don't hesitate or use a little bit of trill. In this passage, the soloist trombone begins with the numbered quarter note, and all notes must be played as sentimental and with inner strength. Each sentence is sung like an aria. The difference between this reproduction and the last one was the addition of the third trumpet, which helped the Trombone solo begin each part. This time, each note can even be slightly weaker. It should be noted and quicker when numbering. Since there is no other part of the voice, each note played here should be maintained, striving to play each note full of time, so that the music can be more fluid. After numbering, the solo part of the solo gradually diminished, as if meditating [4].

\subsection{Playing Techniques}

My breath is marked after the long note and in the rest of the note, which prevents the music from pausing due to breathing and thus allows the music to flow better. In this section, there is also an important support is the beginning of the number, trombone, part and part of the trombone rhythm, this rhythm throughout the beginning of the first movement, many times appear, become an important musical motivation. Since the beginning of the 19th century, with the invention and improvement of the mechanical structure of brass instruments, the performance and performance of the instruments have been greatly improved. This progress has led to the whole orchestra's position in music creation and performance. Among them, trumpet, horn and trombone are the most representative. The charm of instrumental music has begun to be excavated and widely recognized, even exceeding the love of vocal music works. As a composer in the late 20th century with a distinct personal style and a keen interest in exploring the intentions and techniques of composition, Mahler reported great enthusiasm for almost all musical instruments. This rhythm is very important for Trombone solo. In performing, we must pay close attention to listening to the rhythmic patterns played by these three voices. In this way, the solo voice part can have very accurate rhythmic rhythm at any time. Attention should be gradually reduced to, and to maintain, intonation must not be shaken. This requires daily focused breath training. "It is a basic condition for a wind player to control his instrument with a relatively smooth, white and full atmosphere. Starting with the four minute note, each note is basically required to play the stress. When we play these notes, we need courage and we need to speak accurately and 
cleanly. When I vomit, I like to use more breath to match the tongue. When playing the long notes at the end of each phrase, it is necessary to make a gradual weakening to form a clear hierarchy of the phrases. In solo phrases after the numbering, Mahler used written instructions in the score to ask us not to slow down when playing the trilogy. Playing this paragraph is very difficult, because it is a connected weak note, so the pronunciation of the notes should be more difficult soft pronunciation. We can use a bit of trill. Breath is very important in this solo melody. The breath must ensure the consistency and maintenance of each note, and the intensity will gradually decrease.

\section{Philosophical Connotation of Mahler's Symphony}

\subsection{Truth and Falsehood}

At the beginning of the first symphony, Mahler explored his philosophy of life in music. In fact, anything that will form a Muller character has been shown in the first symphony. Here, the song of his life has been played, but it has been expanded and presented to the extreme. Here he shows his love for nature and his thoughts on death. He has been struggling with fate here, and the meaning of this concept is extremely broad to Mahler, it includes not only nature, but also all of life. Although the tragic meaning is not very strong compared with the later similar music, but we can still feel the breath of death from the sad mood. Truth is an integral part of concrete things, and it is a public welfare function of concrete things, behaviors, objects and languages for the survival and development of individuals and social groups. Truth is an integral part of concrete things, and it is a public welfare function of concrete things, behaviors, objects and languages for the survival and development of individuals and social groups. Illusion is a special phenomenon determined by the nature of things and distorted the essence of things. It shows the composer's special sensitivity to death. The fourth movement is full of dramatic intensity, fully revealing his passion, which has overcome life with indomitable strength. The beauty of life, the invasion of death, and the struggle against doom form a stereotyped ideation. Each movement of Song of the Earth uses variations to develop the theme, and the orchestra uses a grand trio. In addition, Mahler intentionally weakened the traditional tonal organization, and the use of dissonances and frequent changes in major and minor made tonality greatly expanded, thus foreshadowing the advent of atonal music in the 20th century. Mahler does not include his works in the category of Title music, but he clearly shows the close relationship between composer's emotional expression, life experience and artistic creation. Mahler objected to the music writing that depended on or closely related to the title music, but he also deeply realized the inner link between the composer's creative inspiration and artistic impulse and the creator's own experience and thinking in his unique life. Mahler's symphony is no longer a traditional genre of pure music, it has become a special artistic carrier to express the humanistic implications to the world and explain the philosophy of life. It not only embodies the philosophical meaning of the First Symphony, but also permeates the ideological connotation of all his symphonies. As the preface to this symphony epic, Symphony No. 1 tells us clearly that the composer's unique thought of exploring the meaning of life marks the further deepening of Mahler's exploration of the meaning of life. These three works are also his attempts to answer these questions from different angles.

\subsection{Love and Hate}

The beginning of the symphony was full of hatred, and the heavy chords, accompanied by the marching speed, seemed so ferocious. In this context, the theme of the main theme in the minor tone forms a deterrent and arrogant trend. The subordinate theme shifted to a major and presented an incomparable sense of beauty in a euphemistic manner, but it was no longer as pure and clear as some of the lyric themes in previous symphonies, but contained a sad mood, reminding people of a painful cry in the face of bad luck. Because the contrast between the two themes is so strong in the presentation, their confrontation in the expansion is bound to enter a white-hot stage. Undoubtedly, the tragic significance of the philosophical ideas of love and hate loaded on these two themes is more profound than ever. Mahler called the Sixth Symphony "Tragic Symphony", which is a natural 
manifestation of deepening tragic consciousness. It is also deeply reflected in the Fifth Symphony and the Seventh Symphony. Such tragic consciousness can only be deepened after the author has tasted the hardship of life and constantly observed the gloomy and cool world. Of course, the refinement and maturity of artistic expression also strengthened the depth of this philosophical idea. The hazy and moving atmosphere makes people naturally associate with a very sweet dream. In this dreamlike music, the atmosphere is illusory, and the emotions it conveys are very real. If we are sweet through this carefully woven dreamy surface, we can taste the bitter and bitter deposits that are deposited in the deep layer.

\subsection{Life and Death}

In contrast, the vocal symphonies "Song of the Earth" and "Ninth Symphony" are more likely to cause the hearer's heart tremor. Art is novel and original, especially the musical language is full of emotional meaning, with the flow of music, and we can hear Mahler's breath of life. The tragic confrontation between life and death has reached the last critical moment. We know that in writing these two works, Mahler has been told that he suffered from serious heart disease. In addition, he has never been free from the painful mood of his beloved daughter, because he felt that he was about to die, so he unlimited longing for life. My longing for life was stronger than ever, and I found that the nature of life was sweeter than ever. Death is coming, life is still making the final struggle, this life and death in the final battle of the heart-stirring scene in the Ninth Symphony in the first movement is very obvious. When the theme of slow and tender appears, what follows is the terrible climax of volcanic eruption. The implication of this change in musical tension is precisely a reflection of the weak struggle of life surrounded by death. Mahler is the successor and developer of the symphony genre at the end of the century. The use of vocal music in his symphony creation has obviously become a routine. The vocal Symphony "Song of the Earth" is composed by an orchestra and two solos. It is the most concise one of Mahler's vocal symphonies. It lays equal stress on both structure and color, and on both vocal and instrumental music. The lyrics are selected from the poems translated from which Mahler selects seven poems with strong contrast in thought and mood, and finally forms the title of the six movements of the work, namely, sad drinking song, autumn silence, youth, beauty, spring drunken man and farewell. Each movement is named after the name of the poem, implying that the work belongs to the category of the title music. From the first movement to the sixth movement, the Chinese pentatonic tone runs through, harmoniously integrating Chinese elements into the Western Symphony genre. This very insightful artistic analysis grasps the true meaning of Mahler's music and is the most convincing interpretation of this complex structure movement. It is worth noting that some passages of these two works are filled with intense passion and tragic feeling. Mahler's exploration of the meaning of life began with optimism, followed by pessimism, and finally reached the climax of emotional sublimation in the pursuit of life full of tragic sense. The tragic meaning of the ultimate proposition "life and death" is fully displayed.

\section{Conclusion}

Music is a kind of apocalypse, which implies philosophical spiritual propositions such as life and destiny in the broadest sense. Although the philosophy of life revealed in music works is metaphorical to the recipient. But this kind of imperceptible purifying spirit effect exists after all. From this point of view, we should pay special attention to the philosophical connotation and cultural value of Mahler's symphony. The greatest value of Mahler's works lies in its highly creative artistic talent and far-reaching eternal value.

\section{References}

[1] Zhang Chen. Eternal Love-Study on Allusion inMahler: Symphony NO.8 [J]. Arts Exploration, 2017, 31(3): 108-118.

[2] Zhang Hongwei. Mahler and His First Symphony [J]. Music Lover, 2018(6): 36-37. 
[3] Li Cuiping. The artistic characteristics of Mahler's vocal symphony “song of earth” [J]. Journal of Jiamusi Vocational Institute, 2013(4): 64+66.

[4] Knecht A S. Gustav Mahler, Symphony No. 9-Budapest Festival Orchestra, Iván Fischer cond-Channel Classics 36115, 2015 (1 CD: 76 minutes), \$20[J]. Nineteenth-Century Music Review, 2017: 1-3. 